\title{
Mirtazapine has a therapeutic potency in 1-methyl-4-phenyl-1,2,3,6-tetrahydropyridine (MPTP)-induced mice model of Parkinson's disease
}

\author{
Naoto Kadoguchi ${ }^{\dagger}$, Shinji Okabe ${ }^{\dagger}$, Yukio Yamamura, Misaki Shono, Tatsuya Fukano, Akie Tanabe, \\ Hironori Yokoyama and Jiro Kasahara ${ }^{*}$
}

\begin{abstract}
Background: Mirtazapine, a noradrenergic and specific serotonergic antidepressant (NaSSA), shows multiple pharmacological actions such as inhibiting presynaptic $a_{2}$ noradrenaline receptor (NAR) and selectively activating 5-hydroxytriptamine (5-HT) 1A receptor $\left(5-\mathrm{HT}_{1 \mathrm{~A}} \mathrm{R}\right)$. Mirtazapine was also reported to increase dopamine release in the cortical neurons with 5-HT dependent manner. To examine whether mirtazapine has a therapeutic potency in Parkinson's disease (PD), we examined this compound in 1-methyl-4-phenyl-1,2,3,6-tetrahydropyridine (MPTP)-treated mice model of PD.
\end{abstract}

Results: Male C57BL/6 mice were subjected to MPTP treatment to establish a PD model. Mirtazapine was administered once a day for 3 days after MPTP treatment. MPTP-induced motor dysfunction, assessed by beam-walking and rota-rod tests, was significantly improved by administration of mirtazapine. Biochemical examinations by high performance liquid chromatography and western blot analysis suggested mirtazapine facilitated utilization of dopamine by increasing turnover and protein expression of transporters, without affecting on neurodegenerative process by MPTP. These therapeutic effects of mirtazapine were reduced by administration of WAY100635, an inhibitor for $5 \mathrm{HT}_{1 \mathrm{~A}} \mathrm{R}$, or of clonidine, a selective agonist for $\mathrm{a}_{2}-\mathrm{NAR}$, or of prazosin, an inhibitor for $a_{1}$-NAR, respectively.

Conclusion: Our results showed mirtazapine had a therapeutic potency against PD in a mouse model. Because PD patients sometimes show depression together, it will be a useful drug for a future PD treatment.

Keywords: 1-methyl-4-phenyl-1,2,3,6-tetrahydropyridine (MPTP), Parkinson's disease, Mirtazapine, Noradrenergic and specific serotonergic antidepressant (NaSSA), Serotonin (5-hydroxytryptamine, 5-HT), Dopamine

\section{Background}

Parkinson's disease (PD) is a progressive, age-related, neurodegenerative disorder characterized by bradykinesia, resting tremor and gait disturbance. The major pathological basis of PD is the death of dopaminergic neurons in the substantia nigra pars compacta $(\mathrm{SNc})$ and the degeneration of their nerve terminals in striatum [1]. It has been proposed that clinical signs of PD appear at the point when

\footnotetext{
* Correspondence: awajiro@tokushima-u.ac.jp

${ }^{\dagger}$ Equal contributors

Department of Neurobiology and Therapeutics, Institute of Health

Bioscience, Graduate School and Faculty of Pharmaceutical Sciences, The University of Tokushima, 1-78, Shoumachi, Tokushima 770-8505, Japan
}

dopaminergic neuronal cell loss exceeds a critical threshold: $70-80 \%$ of striatal nerve terminals and $50-60 \%$ of the SNc perikaryons [2,3]. As a pharmaceutical treatment, L-3,4-dihydroxyphenylalanine (L-dopa), supplying the precursor of dopamine (DA), is the most commonly applied and alleviates major symptom of PD. For over 40 years, treatment with L-dopa combined with an inhibitor for peripheral aromatic L-amino acid decarboxylase (AADC) such as carbidopa had been established as a gold standard for PD treatment $[4,5]$. However, long-term treatment with Ldopa is often complicated by the development of adverse effects such as drug-induced dyskinesia [6]. There have 
been additional anti-parkinsonian drugs, such as dopamine agonists mostly targeted on $\mathrm{D}_{2}$ class receptor, but their pharmaceutical potencies are not drastically better than that of L-dopa. It is essential to develop novel drugs which can support therapeutic effects of L-dopa with delaying expression of its side effects, or even solely effective against PD symptoms.

Serotonergic neurons play an important role in modulating extrapyramidal motor disorders such as PD and drug-induced parkinsonism $[7,8]$. Some studies showed administration of agonists for 1A subtype of serotonin/ 5-hydroxytriptamine receptor $\left(5-\mathrm{HT}_{1 \mathrm{~A}} \mathrm{R}\right.$, e.g., 8-hydroxy2-(di-n-propylamino)tertraline and tandospirone) significantly improved various types of extrapyramidal symptoms including antipsychotic-induced bradykinesia and catalepsy, and neurotoxin-induced bradykinesia [9-11]. Therefore, the central serotonergic system is thought to be one of a favorable drug target for the treatment of PD. It is a well-known fact that serotonergic as well as noradrenergic system is a major target of antidepressants such as selective serotonin-reuptake inhibitor (SSRI) fluoxetine and fluvoxamine. Recently, a novel antidepressant mirtazapine has been developed and is now approved in many countries for clinical treatment of major depression [12]. Mirtazapine is categorized into a noradrenergic and specific serotonergic antidepressant (NaSSA), showing multiple pharmacological actions such as inhibiting presynaptic $\alpha_{2}$ noradrenaline receptor (NAR) and selectively activating $5-\mathrm{HT}_{1 \mathrm{~A}} \mathrm{R}[13,14]$. Mirtazapine has higher antidepressant effects than placebo or trazodone, which is equivalent to the effect of tricyclic antidepressant (TCA) such as clomipramine and amitriptyline [15-17]. Compared to SSRI, mirtazapine showed an earlier onset of antidepressant effects [18]. Further, the side effects of mirtazapine are reported to be lower than those of SSRI or TCA [19].

In 2004, Nakayama et al. reported mirtazapine increased DA release in the medial prefrontal cortex (mPFC) of rats with activating $5-\mathrm{HT}_{1 \mathrm{~A}} \mathrm{R}$ [20]. They reported that 8 or $16 \mathrm{mg} / \mathrm{kg}$ of mirtazapine increased DA release with dose-dependent manner, and an inhibitor of $5-\mathrm{HT}_{1 \mathrm{~A}} \mathrm{R}$ WAY100635 significantly decreased the mirtazapineinduced increase of DA release. We hypothesized mirtazapine may be effective on PD if the same mechanism as this 5-HT-dependent increase of DA release existed in the nigro-striatal dopaminergic system, too. In fact with related to PD, some studies reported the clinical efficacy of mirtazapine on Parkinsonian tremor in human [21,22]. However, little is known about the therapeutic effect of mirtazapine for motor dysfunctions other than tremor in PD. Therefore, in this study, we examined the effect of mirtazapine in mice treated with the neurotoxin 1-methyl-4-phenyl-1,2,3,6-tetrahydropyridine (MPTP), one of the typical animal models of PD [23,24].

\section{Results}

Effect of mirtazapine on motor dysfunctions induced by MPTP

We first assessed effect of mirtazapine on motor dysfunctions induced by MPTP using two different behavioral paradigms: the beam-walking and rota-rod tests.

We chose two doses of mirtazapine ( 4 and $16 \mathrm{mg} / \mathrm{kg}$ ) in this study based on the previous study by Nakayama et al. in 2004 [20] in which they showed 4, 8 and $16 \mathrm{mg} / \mathrm{kg}$ of mirtazapine produced a dose-dependent increase in extracellular DA levels in mPFC of freely moving rats. Thus we examined minimal $(4 \mathrm{mg} / \mathrm{kg})$ and maximal $(16 \mathrm{mg} / \mathrm{kg})$ doses in mice.

In beam-walking test, MPTP-treated mice showed a significantly prolonged duration to traverse a distance of $50 \mathrm{~cm}$ than that of the vehicle-treated mice (Figure 1A; $F_{\text {(A) } 4,44}=9.803, P<0.01$, ANOVA). In contrast, mirtazapine significantly improved the MPTP-induced prolongation of the traversal duration when it was treated after MPTP with both 4 and $16 \mathrm{mg} / \mathrm{kg}$ doses (Figure 1A; $P<0.01$, ANOVA), although it did not affect when solely applied compared to the vehicle-treated mice (Figure 1A, $P>0.05$, ANOVA).

With rota-rod test, vehicle-treated mice usually remained on the rotating rod for approximately 400-600 sec. As shown in Figure 1B, MPTP-treatment significantly decreased the latency to fall from the rod when compared to vehicle-treated mice $(F$ (B) 4,44 $=7.341, P<0.05$, ANOVA). On the other hand, administration of $16 \mathrm{mg} / \mathrm{kg}$ of mirtazapine after MPTP significantly recovered the latency to the level of vehicle-treated group (Figure 1B; $P<0.05$, ANOVA), with no effect when solely applied.

\section{Effect of mirtazapine on the striatal DA, DOPAC, HVA and turnover rate}

Using HPLC, we quantified the striatal DA and its metabolites DOPAC (3,4-dihydroxyphenylacetic acid) and HVA (homovanillic acid) with calculating turnover rate. As shown in Figure 2, administrations of MPTP produced marked depletion of DA, DOPAC and HVA in striatum $\left(F_{(\mathrm{DA})} 4,20=15.423, F_{\text {(DOPAC) }} 4,20=10.767, F_{(\mathrm{HVA})} 4,20=\right.$ 6.643, $P<0.01$, ANOVA), as was reported previously $[25,26]$. DA turnover, calculated by (DOPAC + HVA)/DA [26], was increased significantly by MPTP treatment compared with vehicle $(P<0.01$, Student's $t$-test). Mirtazapine, when solely applied with $16 \mathrm{mg} / \mathrm{kg}$, showed no significant alterations on them when compared with vehicle-treated group (Figure $2 ; P>0.05$, ANOVA). Furthermore, administrations of mirtazapine after MPTP treatment also showed no significant changes on them (Figure 2; $P>0.05$, ANOVA) both with 4 and $16 \mathrm{mg} / \mathrm{kg}$. However, DA turnover was significantly increased by $16 \mathrm{mg} / \mathrm{kg}$ of mirtazapine after MPTP treatment when compared with vehicle or MPTP alone (Figure 2; $F$ (Turnover) 4,20 $=4.951, P<0.05$, 

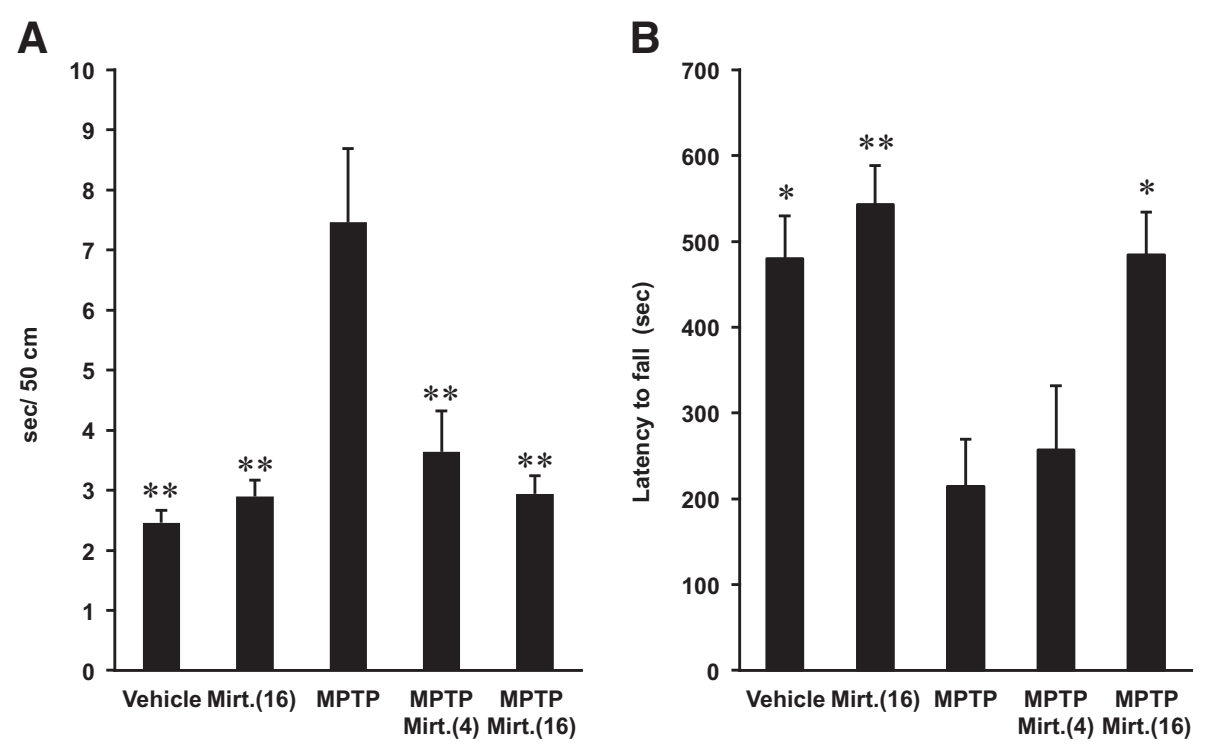

Figure 1 Effects of mirtazapine on MPTP-induced motor dysfunctions in mice using beam-walking test and rota-rod test.

(A) Beam-walking test: Vertical axis shows the periods required to traverse $50 \mathrm{~cm}$ of the beam. (B) Rota-rod test: Vertical axis shows the latency to fall from the rotating rod after the mice were placed on it. Values are expressed as means \pm SEM, $n=9-10$ mice/group. Mirt.(4), mirtazapine $4 \mathrm{mg} / \mathrm{kg}$; Mirt.(16), mirtazapine $16 \mathrm{mg} / \mathrm{kg}$. Statistical significance was evaluated by one-way ANOVA followed by Scheffe test ( $F$ (A) $4,44=9.803, F$ (B) $4,44=7.341,{ }^{*} P<0.05,{ }^{*} P<0.01$ compared with MPTP-treated group).
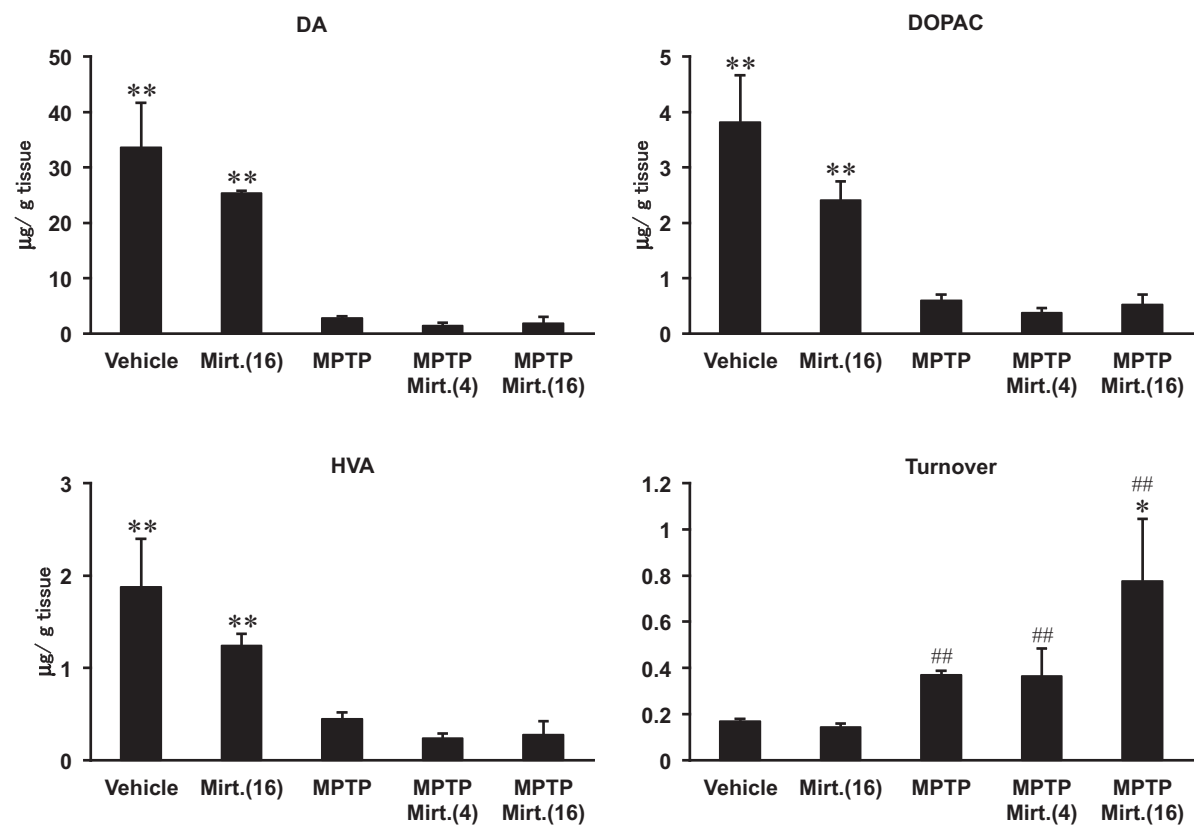

Figure 2 Effects of mirtazapine on the striatal dopamine, DOPAC and HVA contents. Values are expressed as means \pm SEM, $\mathrm{n}=5$ mice/group. Mirt.(4), mirtazapine $4 \mathrm{mg} / \mathrm{kg}$; Mirt.(16), mirtazapine $16 \mathrm{mg} / \mathrm{kg}$. Statistical significance was evaluated by one-way ANOVA followed by Student-Newman-Keuls test $\left(F_{(\mathrm{DA})} 4,20=15.423, F_{\text {(DOPAC) } 4,20}=10.767, F_{\text {(HVA) }} 4,20=6.643, F\right.$ (Turnover) $4,20=4.951,{ }^{*} P<0.05, * * P<0.01$ compared with MPTP-treated group) or by Student's $t$-test $\left({ }^{\#} P<0.01\right.$ compared with vehicle group). 
ANOVA), although it did not affect the basal turnover when solely applied with $16 \mathrm{mg} / \mathrm{kg}$ (Figure 2; $P>0.05$, ANOVA).

\section{Effect of mirtazapine on the striatal TH, DAT and VMAT2 protein expression}

With western blot analysis, we examined protein expression of the dopaminergic markers tyrosine hydroxylase $(\mathrm{TH})$, dopamine transporter (DAT) and vesicle monoamine transporter 2 (VMAT2) in striatum. Treatment with mirtazapine, when solely applied with $16 \mathrm{mg} / \mathrm{kg}$, showed no significant effects on the striatal TH, DAT and VMAT2 protein expression of mice when compared to the vehicletreated group (Figure 3A,B and C; $F$ (TH) 4,17 $=16.115$, $F_{\text {(DAT) }} 4,17=12.386, F$ (VMAT2) $4,19=6.711, P>0.05$, ANOVA), although VMAT2 expression showed a slight tendency of decrease with no significance. MPTP significantly decreased TH, DAT and VMAT2 protein expressions to $20-50 \%$ of the vehicle treated ones (Figure 3A, $\mathrm{B}$ and $\mathrm{C} ; P<0.01$, ANOVA). Mirtazapine did not alter protein expression of $\mathrm{TH}$ when it was applied after MPTP
(Figure 3A; $P>0.05$, ANOVA), strongly suggesting it did not affect the process of neurodegeneration of the nigrostriatal dopaminergic neurons triggered by MPTP. In contrast, mirtazapine showed a dose-dependent tendency of recovery of DAT protein expression, and $16 \mathrm{mg} / \mathrm{kg}$ of mirtazapine showed significant increase of DAT when compared with MPTP-treated group (Figure 3B; $P<0.05$, Student's $t$-test). Furthermore, both 4 and $16 \mathrm{mg} / \mathrm{kg}$ of mirtazapine showed significant recovery of VMAT2 protein expression compared with MPTP-treated group (Figure 3C; $P<0.01$, ANOVA)

\section{Antagonism of WAY100635 on the behavioral effects of mirtazapine}

One of the pharmacological effects of mirtazapine is a selective activation of $5-\mathrm{HT}_{1 \mathrm{~A}} \mathrm{R}$ with blocking both $5-\mathrm{HT}_{2}$ and $5-\mathrm{HT}_{3}$ receptors. To examine the involvement of this mechanism in the effects of mirtazapine, we tested WAY100635, a specific antagonist for $5-\mathrm{HT}_{1 \mathrm{~A}} \mathrm{R}$, together with mirtazapine both on beam-walking and rota-rod tests. In both tests, the therapeutic effects of mirtazapine

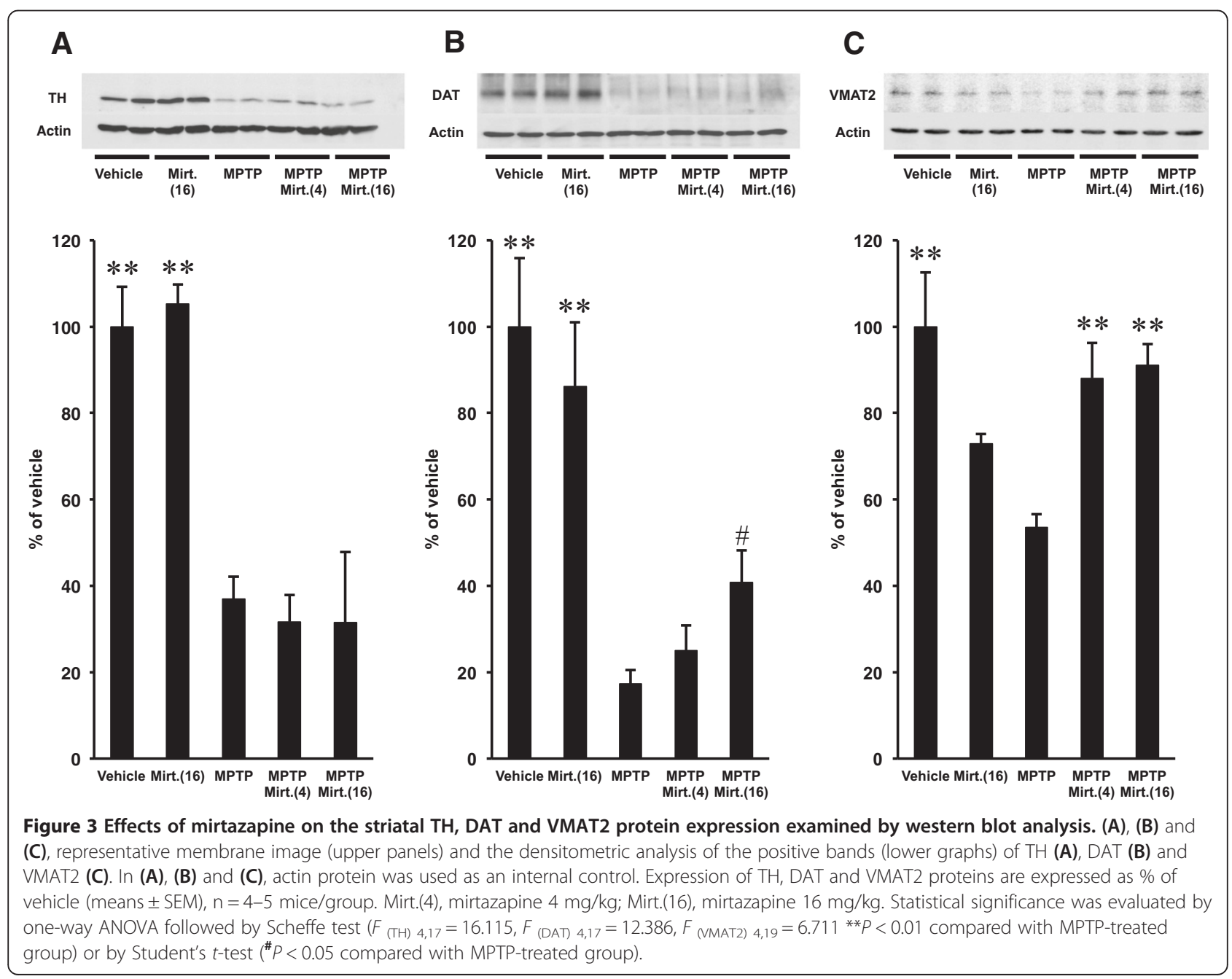


were almost completely cancelled by pre-treatment with $0.5 \mathrm{mg} / \mathrm{kg}$ of WAY100635 (Figure 4A and B; $F_{\text {(A) } 3,35=}$ $18.962, F_{\text {(B) } 3,35}=5.488, P<0.01$, ANOVA).

We also examined the effects of WAY100635 on the basal activities of both tests, and it did not show any significant effects when compared with vehicle-treated group (Figure 5A and B; $F$ (A) 3,36 $=14.476, F$ (B) $3,36=27.092$, $P>0.05$, ANOVA).

\section{Antagonism of prazosin or clonidine on the behavioral effects of mirtazapine}

Because noradrenergic system regulates both DA and 5HT neurons [27-29] and $\alpha_{2}$-NAR is one of an inhibitory target of mirtazapine, we tested prazosin, an antagonist for $\alpha_{1}$-NAR, or clonidine, selective agonist for $\alpha_{2}-\mathrm{NAR}$, together with mirtazapine both on beam-walking and rota-rod tests. As shown in Figure 6A and B, both of the noradrenergic drugs significantly reduced the effects of mirtazapine (Figure 6A and B; $F$ (A) 4,45 = 15.060, $F_{\text {(B) } 4,45}=13.097, P<0.01$, ANOVA), although their effect in beam-walking test was incomplete when compared to that of WAY100635.

As we did in the previous section using WAY100635, we also examined both of the noradrenergic drugs on the basal behavioral activities of beam-walking and rota-rod tests. In beam-walking test, prazosin did not affect the periods for traversing $50 \mathrm{~cm}$, although clonidine significantly increased it (Figure 5A; $P<0.01$, ANOVA). In rota-rod test, both prazosin and clonidine significantly shortened the latency to fall from the rotating rod (Figure 5B; $P<0.01$, ANOVA), suggesting some of the effects we have observed contain basal disturbance of these drugs on autonomic system.

\section{Antagonism of WAY100635, prazosin and clonidine on the biochemical effects of mirtazapine}

We also examined the effects of WAY100635, prazosin and clonidine on the contents of the striatal DA and its metabolites with turnover rate of DA by HPLC both in the vehicle and MPTP-treated mice. As shown in Table 1, all of three drugs have no effects on basal DA, DOPAC and HVA contents, although prazosin and clonidine decreased basal DA turnover significantly when compared with vehicle-treated group (Table $1 ; P<0.05$ and $P<0.01$, respectively, Student's $t$-test). When these three drugs were administered prior to mirtazapine, all of them significantly reduced the increased DA turnover observed in MPTP + mirtazapine group (Table 1; $F$ (Turnover) $8,40=$ 4.232, $P<0.05$, ANOVA).

\section{RT-PCR detection of mRNA for the isoforms of noradrenaline and serotonin receptors}

To examine whether the known receptors, which could be affected with mirtazapine directly or for the targets of
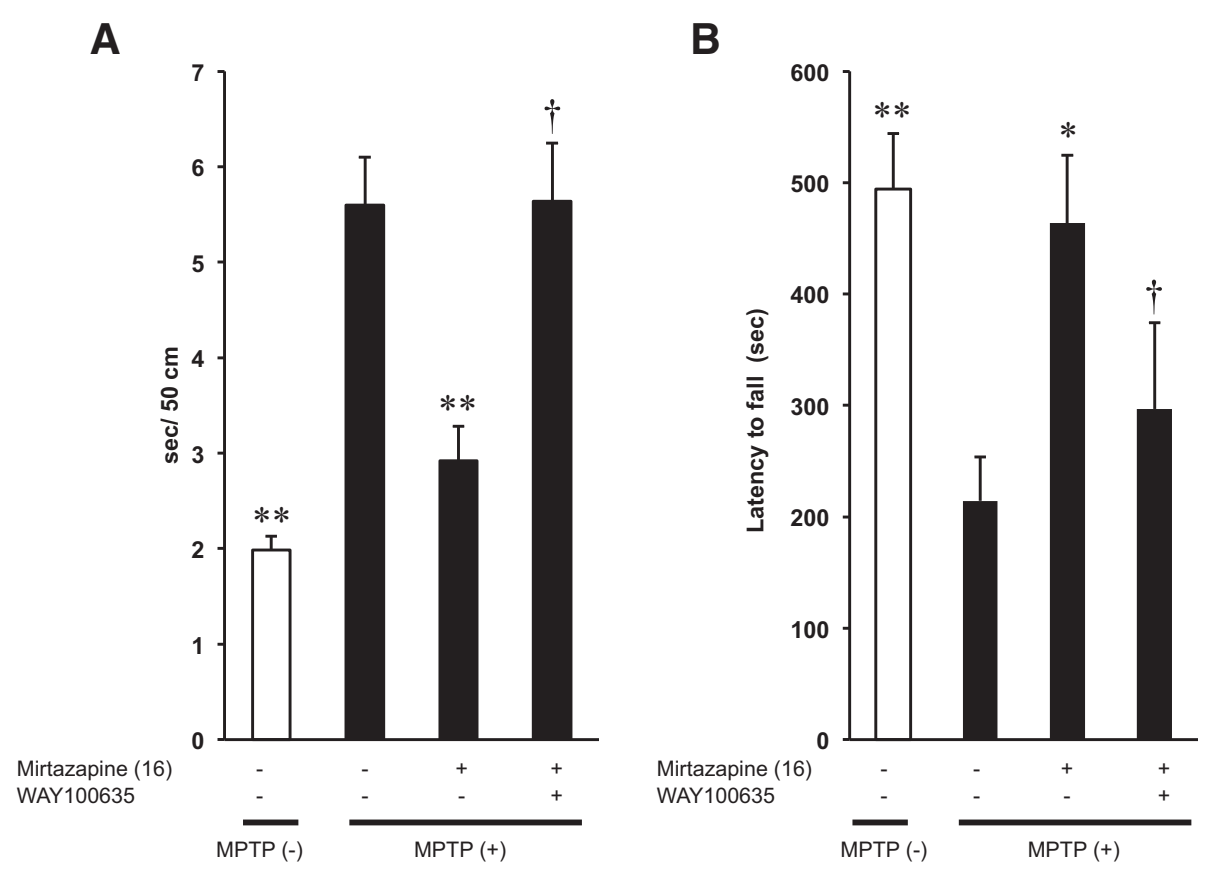

Figure 4 Inhibition of the behavioral effects of mirtazapine by WAY100635 on beam-walking test and rota-rod test. (A) Beam-walking test: Vertical axis shows the periods required to traverse $50 \mathrm{~cm}$ of the beam. (B) Rota-rod test: Vertical axis shows the latency to fall from the rotating rod after the mice were placed on it. Values are expressed as means $\pm S E M, n=9-10$ mice/group. Statistical significance was evaluated by one-way ANOVA followed by (A) Scheffe test and (B) Student-Newman-Keuls test. $\left(F\right.$ (A) $3,35=18.962, F$ (B) $3,35=5.488,{ }^{*} P<0.05$, ${ }^{* *} P<0.01$ compared with MPTP-treated group and ${ }^{\dagger} P<0.05$ compared with MPTP + mirtazapine group). 
A

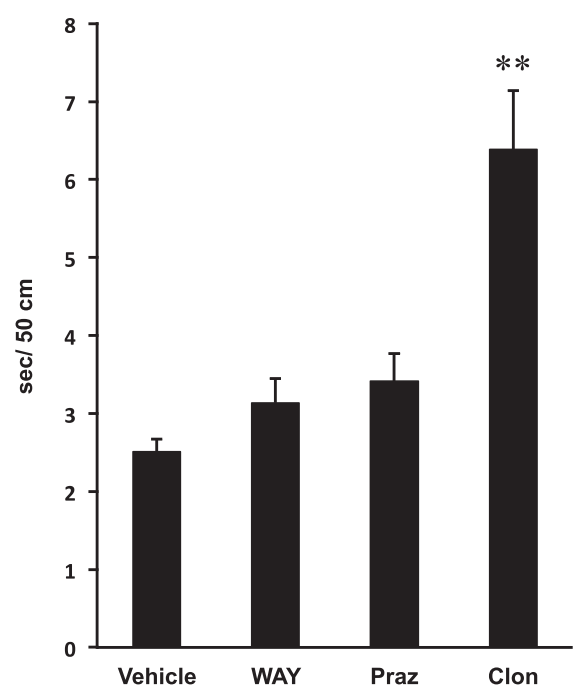

B

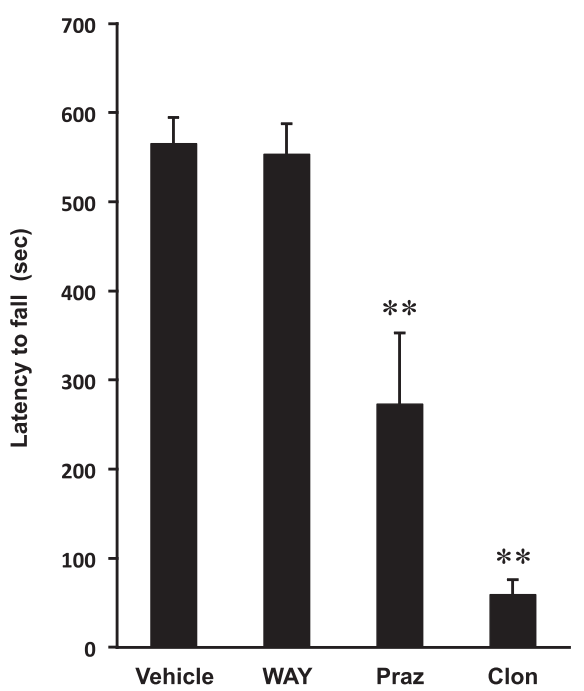

Figure 5 Effects of WAY100635, prazosin or clonidine on basal motor activity of normal mice. (A) Beam-walking test: Vertical axis shows the periods required to traverse $50 \mathrm{~cm}$ of the beam. (B) Rota-rod test: Vertical axis shows the latency to fall from the rotating rod after the mice were placed on it. Values are expressed as means \pm SEM, $n=10$ mice/group. WAY, WAY100635; Praz, prazosin; Clon, clonidine. Statistical significance was evaluated by one-way ANOVA followed by Scheffe test $\left(F(\right.$ A $) 3,36=14.476, F(B) 3,36=27.092,{ }^{* *} P<0.01$ compared with vehicle group).

the inhibitors used in this study, are expressed in striatum, SNc and raphe nucleus, we performed RT-PCR. The specific primers used to detect mRNAs for the noradrenaline and 5-HT receptors, $\alpha_{1 \mathrm{~A}}, \alpha_{1 \mathrm{~B}}, \alpha_{1 \mathrm{D}}, \alpha_{2 \mathrm{~A}}, \alpha_{2 \mathrm{~B}}$, $5-\mathrm{HT}_{1 \mathrm{~A}}, 5-\mathrm{HT}_{2 \mathrm{~A}}, 5-\mathrm{HT}_{2 \mathrm{~B}}, 5-\mathrm{HT}_{2 \mathrm{C}}$ and $5-\mathrm{HT}_{3}$ are written in Methods. As shown in Figure 7, $\alpha_{1 \mathrm{~A}}, \alpha_{1 \mathrm{~B}}, \alpha_{1 \mathrm{D}}, \alpha_{2 \mathrm{~A}}$ and $\alpha_{2 B}$ noradrenaline receptors were expressed in striatum, SNc and raphe. On the other hand, no $5-\mathrm{HT}_{2 \mathrm{~B}} \mathrm{R}$ transcript was detected in $\mathrm{SNc}$ and raphe, while $5-\mathrm{HT}_{1 \mathrm{~A}}$, $5-\mathrm{HT}_{2 \mathrm{~A}}, 5-\mathrm{HT}_{2 \mathrm{C}}$ and $5-\mathrm{HT}_{3}$ receptors were detected in striatum, SNc and raphe (Figure 7).

\section{Discussion}

In the present study, we found that treatment with mirtazapine in mice significantly improved MPTP-induced motor dysfunction. To our knowledge, this is the first report showing the therapeutic potency of an antidepressant mirtazapine against MPTP neurotoxicity in mice. Because MPTP mice are one of the most popular models for screening anti-PD agents [23-26,30], our results suggest possible use of mirtazapine as a PD therapeutics in clinical patients.

Our results of HPLC in Figure 2 and Table 1 showed MPTP increased DA turnover in striatum, and mirtazapine further elevated it. Similar results were reported previously by zonisamide, an anti-convulsant drug also effective on PD [26]. Increased DA turnover with MPTP treatment is thought as a compensatory effect exerted by the remained DA neurons under the neurotoxic condition [26,31], although significant behavioral deficits (Figure 1) suggested the compensatory effect was insufficient to keep the normal motor coordination. Further elevation of DA turnover with mirtazapine after MPTP treatment observed in this study led us to speculate mirtazapine facilitate utilization of DA, probably by increasing DA release, reuptake, degradation and/or recycling in the DA-depleted condition. Supporting this idea, in fact, reduced protein expression of DAT by MPTP was partially recovered, and that of VMAT2 was almost completely recovered to the normal level by mirtazapine (Figure 3B and C). The increase of these transporter proteins would reflect the increased DA release from the dopaminergic nerve terminals in striatum by mirtazapine [32,33]. In contrast, reduction of TH expression with MPTP was not rescued by mirtazapine (Figure 3A), suggesting it did not affect on the neurodegenerative process of MPTP.

The effect of mirtazapine in our study was expressed specifically after the treatment of MPTP, and the sole treatment with mirtazapine did not alter the behavioral parameters (Figure 1) nor the striatal contents of DA and its metabolites with DA turnover (Figure 2 and Table 1), whereas the previous report of Nakayama et al. [20] showed increased DA release by acute and sole treatment of mirtazapine in mPFC of rats. The discrepancy is probably caused by following differences: schedule of drug administration, method and timing of sampling, method of analysis especially because the lack of real-time measurement of extracellular DA levels in our study. Nevertheless of the discrepancy, these results suggest increase of DA by mirtazapine in the rodent brain with a short-term administration. Other study, however, reported that two-week administration of mirtazapine completely antagonized the 
A

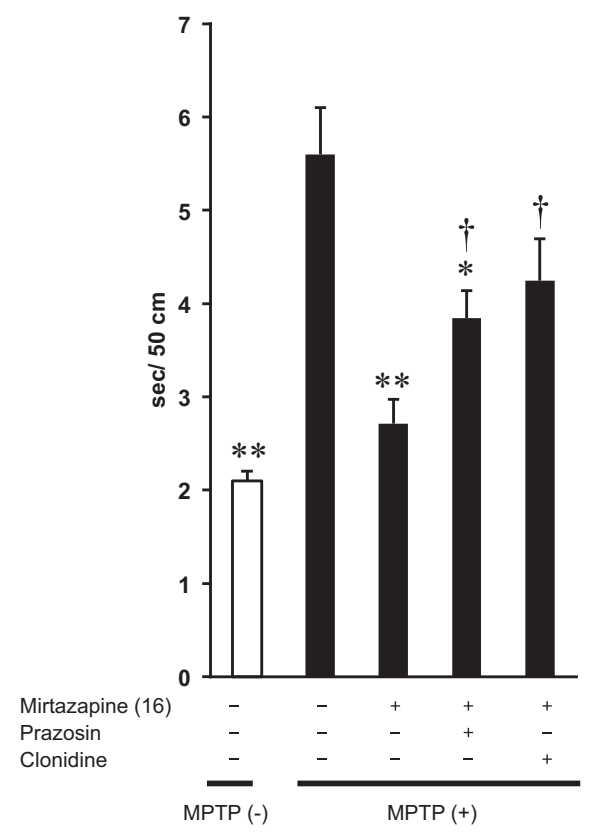

B

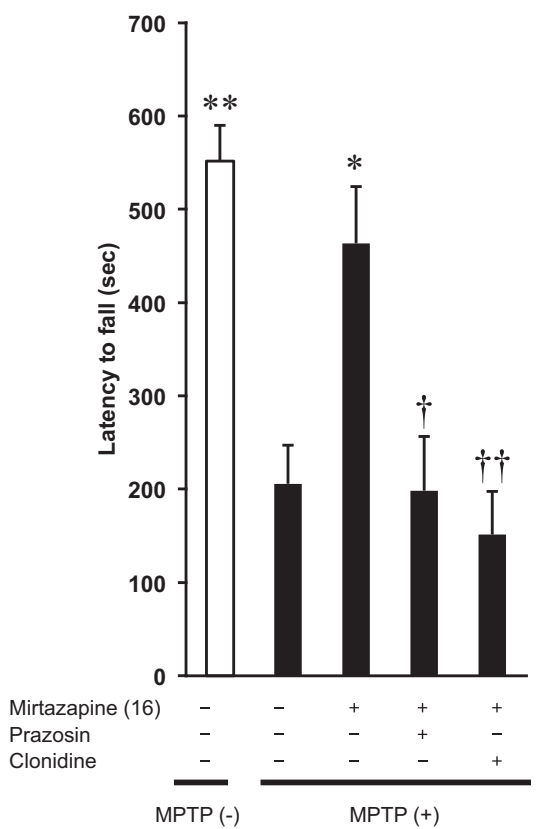

Figure $\mathbf{6}$ Inhibition of the behavioral effects of mirtazapine by prazosin or by clonidine. (A) Beam-walking test: Vertical axis shows the periods required to traverse $50 \mathrm{~cm}$ of the beam. (B) Rota-rod test: Vertical axis shows the latency to fall from the rotating rod after the mice were placed on it. Values are expressed as means \pm SEM, $n=10$ mice/group. Statistical significance was evaluated by one-way ANOVA followed by (A) Student-Newman-Keuls test and (B) Scheffe test $\left(F(A) 4,45=15.060, F\right.$ (B) $4,45=13.097,{ }^{*} P<0.05,{ }^{*} P<0.01$ compared with MPTP-treated group and ${ }^{{ }^{\dagger}} P<0.01,{ }^{\dagger} P<0.05$ compared with MPTP + mirtazapine group).

stress-induced increase in dopamine release in the prefrontal cortex [34]. It may be possible that the pharmacological action of miratazapine is different depending on the periods of administration and the amount of DA at the targeted synapses. Further examination using microdialysis in striatum measuring extracellular DA, NA and 5HT with their metabolites will explore more precise mechanisms of both acute and chronic action of mirtazapine including the hypothesis shown in Figure 8.
As mentioned in Introduction, mirtazapine is categorized into NaSSA, inhibiting pre-synaptic $\alpha_{2}$-NAR specifically. Mirtazapine also inhibits $5-\mathrm{HT}_{2}$ and $5-\mathrm{HT}_{3}$ receptors which in turn selectively activate $5-\mathrm{HT}_{1} \mathrm{R}$. It enhances, therefore, the release of noradrenaline and $5-\mathrm{HT}_{1 \mathrm{~A}} \mathrm{R}$-mediated serotonergic transmission [35]. Based on these pharmacological properties of mirtazapine and from our results of the experiments using NAR- and 5-HTR-related reagents, we illustrated a hypothetical mechanism of

Table 1 The effect of WAY100635, prazosin or clonidine on the striatal dopamine, DOPAC and HVA

\begin{tabular}{|c|c|c|c|c|}
\hline & Dopamine & DOPAC & HVA & Turnover rate \\
\hline Vehicle & $19.49 \pm 0.75^{* *}$ & $1.62 \pm 0.12^{* *}$ & $1.03 \pm 0.04^{* *}$ & $0.14 \pm 0.01$ \\
\hline WAY100635 (0.05 mg/kg) & $18.22 \pm 1.21^{* *}$ & $1.73 \pm 0.09^{* *}$ & $0.91 \pm 0.04^{* *}$ & $0.15 \pm 0.01$ \\
\hline prazosin $(0.03$ mg/kg) & $20.27 \pm 2.33^{* *}$ & $1.51 \pm 0.14^{* *}$ & $0.79 \pm 0.09^{* *}$ & $0.12 \pm 0.01^{\#}$ \\
\hline clonidine $(0.15$ mg/kg) & $22.76 \pm 1.88^{* *}$ & $1.47 \pm 0.07^{* *}$ & $0.84 \pm 0.05^{* *}$ & $0.10 \pm 0.01^{\# \#}$ \\
\hline MPTP & $3.38 \pm 0.35$ & $0.51 \pm 0.05$ & $0.44 \pm 0.04$ & $0.28 \pm 0.01^{\# \#}$ \\
\hline MPTP + mirtazapine (16 mg/kg) & $1.90 \pm 1.21$ & $0.38 \pm 0.08$ & $0.29 \pm 0.06$ & $0.78 \pm 0.25^{*}$ \\
\hline MPTP + mirtazapine (16 mg/kg) + WAY100635 (0.05 mg/kg) & $2.25 \pm 0.47$ & $0.40 \pm 0.10$ & $0.32 \pm 0.08$ & $0.33 \pm 0.05^{\dagger}$ \\
\hline MPTP + mirtazapine $(16$ mg/kg) + prazosin (0.03 mg/kg) & $3.49 \pm 0.48$ & $0.56 \pm 0.04$ & $0.37 \pm 0.01$ & $0.28 \pm 0.03^{\dagger}$ \\
\hline MPTP + mirtazapine $(16$ mg/kg) + clonidine $(0.15$ mg/kg) & $2.90 \pm 0.68$ & $0.58 \pm 0.68$ & $0.45 \pm 0.07$ & $0.31 \pm 0.04^{\dagger}$ \\
\hline
\end{tabular}

The results are shown as the mean $(\mu \mathrm{g} / \mathrm{g}$ tissue) \pm SEM of $4-6$ animals/group. Statistical significance was evaluated by Student-Newman-Keuls test $(F$ (DA) $8.40=84.267$, $F_{\text {(DOPAC) } 8,40}=32.896, F_{\text {(HVA) } 8,40}=29.578, F$ (Turnover) $8,40=4.232,{ }^{*} P<0.05,{ }^{* *} P<0.01$ compared with MPTP-treated group and ${ }^{\dagger} P<0.05$ compared with MPTP + mirtazapine group), or by Student's $t$-test ( ${ }^{\#} P<0.05,{ }^{\# \#} P<0.01$ compared with vehicle group). 


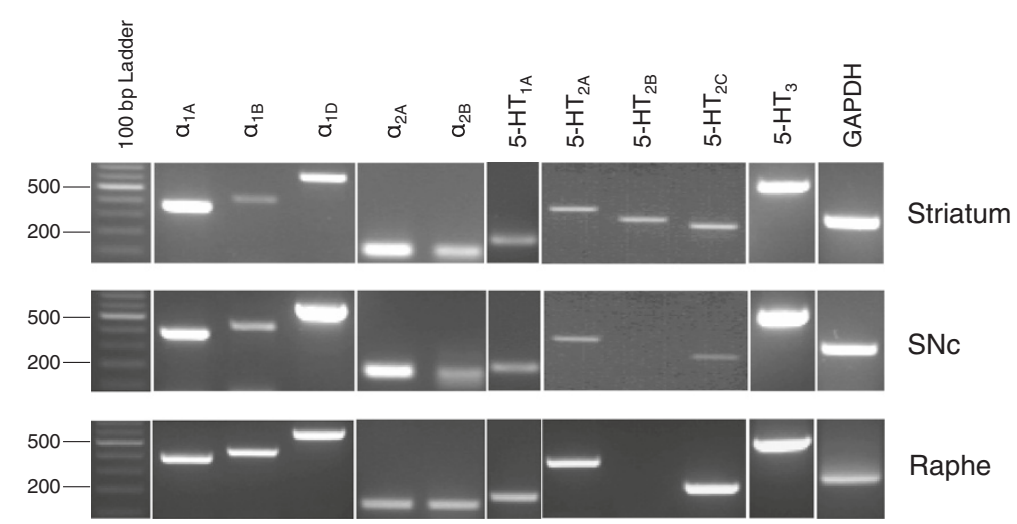

Figure 7 RT-PCR detection of mRNAs for the isoforms of NA and 5-HT receptors. RT-PCR was performed as described in Methods. PCR products were subjected to agarose gel electrophoresis, and the gel images with UV detection are shown.

mirtazapine action on PD-related nigro-striatal dopaminergic system with serotonergic and noradrenergic systems (Figure 8). WAY100635, a selective inhibitor for $5-\mathrm{HT}_{1 \mathrm{~A}} \mathrm{R}$, clearly cancelled the therapeutic effects of mirtazapine on MPTP-induced neurotoxicity without affecting the basal behavioral or the biochemical parameters (Figures 4 and 5 , Table 1), strongly suggest the involvement of this receptor for the effects of mirtazapine. From the dorsal raphe nuclei, 5-HT neurons innervate directly to the nigral DA neurons to inhibit the firing of them with $5-\mathrm{HT}_{2 \mathrm{~A}} \mathrm{R}$-dependent manner [28,36]. Inhibition of this
$5-\mathrm{HT}_{2 \mathrm{~A}} \mathrm{R}$ by mirtazapine results in increase of DA release. Further, the recurrent innervation of 5-HT neurons via $5-\mathrm{HT}_{1 \mathrm{~A}} \mathrm{R}$ in raphe negatively controls cell firing and release of $5-\mathrm{HT}$ [37]. Thus, activation of $5-\mathrm{HT}_{1 \mathrm{~A}} \mathrm{R}$ by mirtazapine can reduce 5-HT release, and it also results in the increased DA release. In fact, our RT-PCR results showed expression of both $5-\mathrm{HT}_{2 \mathrm{~A}} \mathrm{R}$ mRNA in $\mathrm{SNc}$ and $5-\mathrm{HT}_{1 \mathrm{~A}} \mathrm{R}$ in raphe (Figure 7). Recently, it has been reported that $5-\mathrm{HT}_{2 \mathrm{~A}} \mathrm{R}$ antagonists M100907 improved motor impairments in the MPTP-induced mouse model of PD [38]. Other studies also revealed that stimulation of

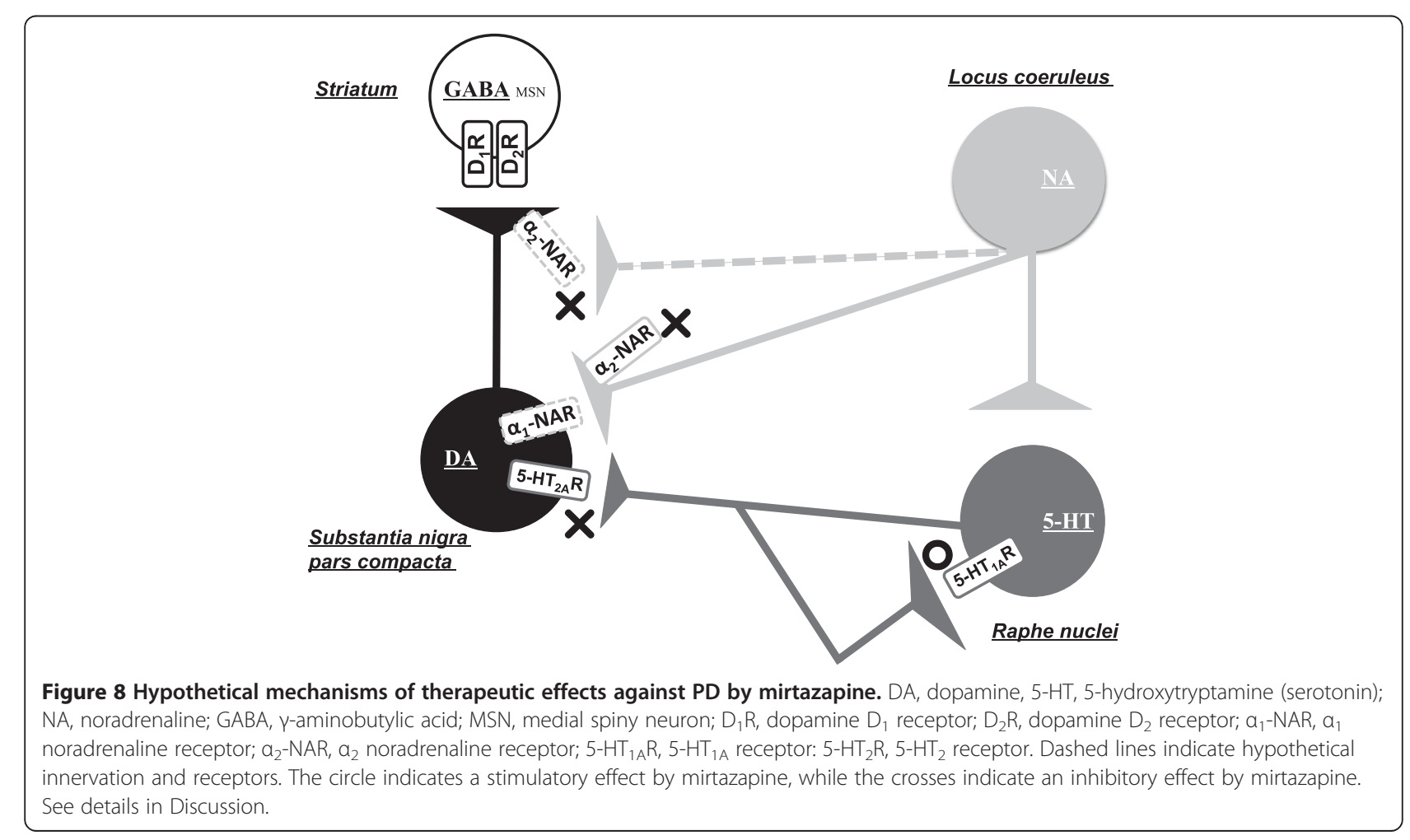


$5-\mathrm{HT}_{1 \mathrm{~A}} \mathrm{R}$ recovered the motor disorders caused by lesions of DA neurons or DA depletion [39-42]. Thus, both 5$\mathrm{HT}_{1 \mathrm{~A}} \mathrm{R}$ and $5-\mathrm{HT}_{2 \mathrm{~A}} \mathrm{R}$ are attractive targets as novel PD therapeutics. $\alpha_{2}$-NAR is another inhibitory target of mirtazapine. In fact, clonidine, a selective agonist for this receptor reduced the effects of mirtazapine, although it also affected basal activity of mice and striatal DA turnover (Figures 6 and 5, Table 1), probably of its inhibitory effect on peripheral sympathetic system. Noradrenaline inhibits the neurotransmitter release via presynaptic $\alpha_{2}$ NAR, and mirtazapine increases neurotransmitter release by inhibiting this receptor [13,14]. Although precise mechanism is still unknown, we speculate this receptor could also function as presynaptic hetero receptor on DA neuron to regulate DA release negatively, the same as presynaptic autoreceptor on noradrenergic nerve terminal (Figure 8). Actually we detected $\alpha_{2 \mathrm{~A}}$ and $\alpha_{2 \mathrm{~B}}$ mRNA isoforms both in striatum and SNc (Figure 7). Prazosin, an antagonist for $\alpha_{1}$-NAR, also showed similar effects as clonidine. We suppose noradrenergic input on DA would activate DA neuron via $\alpha_{1}$-NAR in SNc as illustrated in Figure 8 , since similar stimulatory mechanism was reported in 5-HT and other neurons [43]. However, we could not clearly discriminate peripheral and central effects of the noradrenergic drugs in this study. It will be difficult to use clonidine $(0.15 \mathrm{mg} / \mathrm{kg})$ and prazosin $(0.03 \mathrm{mg} / \mathrm{kg})$ to address the mechanism for mirtazapine effect in this mouse model with a systemic administration. Precise mechanism of the effect of mirtazapine through noradrenergic system should be examined, with applying more specific inhibitors directly into specific brain regions, for example.

It is a well known fact that long-term treatment of Ldopa in PD patients causes various adverse side effects such as wearing-off, dyskinesia, psychiatric symptoms, and so on $[44,45]$. A recent study has demonstrated that treatment with a SSRI fluoxetine significantly suppressed L-dopa-induced rotational behavior in 6-hydroxydopamine (6-OHDA)-treated rats with $5-\mathrm{HT}_{1 \mathrm{~A}} \mathrm{R}$-dependent manner [46]. Furthermore, a selective $\alpha_{2}$-NAR antagonist fipamezole reduced L-dopa-induced dyskinesias in MPTP-treated monkeys [47]. These observations suggest that NaSSA mirtazapine could be a possible novel therapeutic drug for PD, particularly in regard to avoiding the adverse side effects of L-dopa. Depression in PD patients is the most common psychiatric disturbance [48], and SSRIs are now often used for the treatment [49]. Recently, NaSSA is also used and shown to be effective in the treatment of depression in PD patients as well as SSRI [48,50]. However, the effect of NaSSA on motor dysfunction in PD patients is still unknown. Together with these reports and our results in this study, it is highly expected that mirtazapine has dual therapeutic effects both on depression and PD in humans. Our study here and further detailed examinations will open the next door of clinical trial to examine mirtazapine on PD.

\section{Conclusion}

Our present study provides the first evidence that mirtazapine has a therapeutic potency against MPTP neurotoxicity in mice. Because PD patients sometimes show depression together, it is highly expected that mirtazapine has dual therapeutic effects both on depression and PD in humans.

\section{Methods}

\section{Experimental animals}

Male C57BL/6 mice (Nihon SLC Co., Shizuoka, Japan), 8 weeks of age, were used in this study. The animals were housed in a controlled environment $\left(23 \pm 1^{\circ} \mathrm{C}, 50 \pm 5 \% \mathrm{hu}-\right.$ midity) and were allowed food and tap water ad libitum. The room lights were on between 8:00 and 20:00. All handlings and procedures of animal experiments were performed in accordance with the National Institute of Health guide for the care and use of Laboratory animals (NIH Publications No. 8023, revised 1978), and approved by the Committee for Animal Experiments of the University of Tokushima (\#10138).

\section{Drug treatments}

Mice were injected with $20 \mathrm{mg} / \mathrm{kg}$ of MPTP (SigmaAldrich, St. Louis, MO, USA) or saline intraperitoneally (i.p.) every $2 \mathrm{hr}$ for a total of four injections, resulting in a cumulative dose of $80 \mathrm{mg} / \mathrm{kg}$, as described previously [51]. Mirtazapine (generously provided by Meiji Seika Pharma Co., Ltd., Japan) was dissolved in $0.5 \%$ carboxymethylcellulose, and was applied once a day with 4 or $16 \mathrm{mg} /$ kg i.p. started from $1 \mathrm{hr}$ after the final MPTP treatment for 4 days. WAY100635 (0.5 mg/kg, Sigma-Aldrich, St. Louis, MO, USA), prazosin (0.03 mg/kg, Sigma-Aldrich, St. Louis, MO, USA) and clonidine $(0.15 \mathrm{mg} / \mathrm{kg}$, SigmaAldrich, St. Louis, MO, USA) were dissolved in saline, and each of them was administered $1 \mathrm{hr}$ before treating with mirtazapine.

\section{Behavioral testing}

Three days after MPTP or saline treatment, behavioral tests were performed $1 \mathrm{hr}$ after the final treatment with mirtazapine or vehicle. For the behavioral analysis, we examined with two different experimental paradigms.

\section{Beam-walking test}

The apparatus used in this experiment was a modification of that used by Allbutt and Henderson [52]. Before MPTP treatment, mice were trained to transverse a wooden round beam with $12 \mathrm{~mm}$ diameter, $80 \mathrm{~cm}$ length, suspended $55 \mathrm{~cm}$ above the floor, in two consecutive trains 
with 3 hr intervals each day for 3 days. Three days postMPTP or saline treatment, mice were subjected to trials on the beam with $8 \mathrm{~mm}$ rather than $12 \mathrm{~mm}$ diameter during which they were video-recorded. The time to reach a distance of $50 \mathrm{~cm}$ was measured.

\section{Rota rod test}

The Rota rod treadmill (Constant Speed Model, Ugo Basile, Varese, Italy) consists of a plastic rod, $6 \mathrm{~cm}$ in diameter and $36 \mathrm{~cm}$ long, with a non-slippery surface $20 \mathrm{~cm}$ above the base (trip plate). This rod is divided into five equal sections by six discs ( $25 \mathrm{~cm}$ in diameter), which enables five mice to walk on the rod at the same time. In the present study, rotor mode with a constant speed was used. All the mice used were subjected to one training session a day for 3 consecutive days before MPTP treatment with $20 \mathrm{rpm}$ for $10 \mathrm{~min}$. At the trial session performed 3 days after MPTP treatment, the latency to fall of the animals from the rotating rod (32 rpm for $10 \mathrm{~min}$ ) after they were placed on it was recorded as the performance time, as described previously [25].

\section{Quantification of DA and its metabolites}

The mice were killed by cervical dislocation 3 days after the final treatment with saline or MPTP. The striatum were rapidly dissected out on ice and sonicated in ice-cold $50 \mathrm{nM}$ perchloric acid containing $1 \mu \mathrm{g} / \mathrm{ml}$ isoproterenol as an internal standard. DA, DOPAC and HVA were quantified by HPLC with an electrochemical detector (ECD) (Eicom, Kyoto, Japan). Concentrations of dopamine and its metabolites were expressed as $\mu \mathrm{g} / \mathrm{g}$ tissue weight, as described previously $[53,54]$.

\section{Western blot analysis}

The striatal tissues were homogenized in $(50 \mathrm{mM}$ Tris$\mathrm{HCl}, \mathrm{pH}$ 7.5, $0.5 \mathrm{M} \mathrm{NaCl}, 0.5 \%$ Triton X-100, $10 \mathrm{mM}$ EDTA, $4 \mathrm{mM}$ EGTA, $1 \mathrm{mM} \mathrm{Na} \mathrm{VO}_{4}, 30 \mathrm{mM} \mathrm{Na} \mathrm{m}_{2} \mathrm{O}_{7}$, $50 \mathrm{mM}$ NaF, $0.1 \mathrm{mM}$ leupeptin, $0.075 \mathrm{mM}$ pepstatin $\mathrm{A}$, $0.05 \mathrm{mg} / \mathrm{ml}$ trypsin inhibitor, $1 \mathrm{mM}$ phenylmethanesulfonyl fluoride, $100 \mathrm{nM}$ calyculin $\mathrm{A}$, and $1 \mathrm{mM}$ dithiothreitol) using a microtube homogenizer. Insoluble materials were removed by centrifugation at 15,000 rpm (CT15RE, HITACHI, Ibaragi, Japan) for $10 \mathrm{~min}$. The supernatants were mixed with Laemmli's sample buffer (final concentrations, $63 \mathrm{mM}$ Tris- $\mathrm{HCl}, \mathrm{pH}$ 6.8, 2\% SDS, 5\% $\beta$-mercaptoethanol, 2.5\% glycerol, and $0.0083 \%$ bromphenol blue) and boiled for $5 \mathrm{~min}$. Protein concentrations of the sample were determined using the Bradford protein assay. Ten micrograms of protein from each sample were separated on $12 \%$ sodium dodecyl sulfatepolyacrylamide gel electrophoresis (SDS-PAGE) gel using constant current. Separated proteins were transferred to polyvinylidene difluoride (PVDF) membranes at $75 \mathrm{~V}$ for 1.5 hr using a Trans Blot Cell (Bio-Rad, CA, USA). The membranes were incubated for $1 \mathrm{~h}$ at room temperature with Tris-buffered saline containing 0.1\% Tween 20 (TBST) and $0.5 \%$ skim milk, followed by overnight incubation at $4^{\circ} \mathrm{C}$ with desired primary antibodies. The anti-TH antibody (1:1000, Chemicon International, Inc., Temecula, CA, USA) and anti-DAT antibody (1:1000, Chemicon International Inc., Temecula, CA, USA) as a marker of dopaminergic neurons were used. The anti-VMAT2 antibody (1:500, Santa Cruz Biotechnology, CA, USA) as a maker of presynaptic components was used. Membranes were washed six times for $5 \mathrm{~min}$ each at room temperature and incubated with horseradish peroxidase-conjugated secondary antibody in TBST for $1 \mathrm{hr}$. Immunoreactive bands were visualized by enhanced chemiluminescent autoradiography (ECL Kit, GE healthcare, Buckinghamshire, UK), according to manufacturer's instructions. Actin antibody (Sigma, Saint Louis, MO, USA) was used as a house keeping protein to confirm that equal amounts of protein were loaded in each line. Optical densities were determined using a computerized image analysis system (Dolphin-DOC, Kurabo, Osaka, Japan), as described previously $[25,55]$.

\section{RNA isolation and RT-PCR}

Total RNA from striatum, SNc or raphe was purified using RNAiso plus (Takara Bio, Tokyo, Japan) according to manufacturer's protocol. Reverse transcription from RNA to cDNA was performed using M-MLV reverse transcriptase and other supplements (Promega, Madison, WI, USA). Polymerase chain reaction (PCR) with GoTaq Green (Promega, Madison, WI, USA) was performed with using glyceraldehyde phosphate dehydrogenase (GAPDH) as an internal control. The following primers for mouse noradrenaline and 5-HT receptors with GAPDH were used (name, accession number, forward (F) or reverse (R) primer sequence, product length):

$\alpha_{1 \mathrm{~A}}$, NM_07417, (F) CGACAAGTCAGACTCAGAG CAAGTGA,

(R) TGTAGCCCAGGGCATGCTTGGAAGAC, 403 bp; $\alpha_{1 \mathrm{~B}}$, NM_007416, (F) TTTCATGAGGACACCCTCA GCAGTACC,

(R) CTGCCACTGTCATCCAGAGAGTCC, 451 bp;

$\alpha_{1 \mathrm{D}}$, NM_013460, (F) CGCCAAAGGAAATCCAGGG $\mathrm{ACAC}$,

(R): CAGAGCGGAACTTATGGGACAGG, 616 bp; $\alpha_{2 A}$, NM_013461, (F) TTCTTTTTCACCTACACGC TCA,

(R) TGTAGATAACAGGGTTCAGCGA, $121 \mathrm{bp}$; $\alpha_{2 B}$, NM_009633, (F) ACCTTCCCTTGCTGACTGT $\mathrm{ACT}$,

(R) TGGGAGGGAGGTATTCTAATCA, 111 bp; 5HT $\mathrm{HA}_{1 \mathrm{~A}}$, NM_008303, (F) TGCTCATGCTGGTCCTC TAT,

(R) TCTCAGCACTGCGCCTGC, 179 bp; 


\author{
5HT $2 \mathrm{~A}$, NM_172812, (F) AAGCCTCGAACTGGACA \\ ATTGATG, \\ (R) TGATTTTCAGGAAGGCTTTGGTT, 477 bp; \\ 5HT ${ }_{2 B}$, NM_008311, (F) CTCGGGGGTGAATCCTC \\ TGA,
(R) CCTGCTCATCACCTCTCTCAG, 366 bp; 5HT ${ }_{2 \mathrm{C}}$, NM_008312, (F) CAGATCAGAAGCCACGT \\ CGA, \\ (R) GGCTTATAATCGCAGCGCAA, 318 bp; \\ 5HT ${ }_{3}$, NM_013561, (F) GCCACCCAGGCCCGAGA \\ TAC, \\ (R) GCTCCCACTCGCCCTGATTT, 564 bp; \\ GAPDH, M32599, (F) GCCAAAGGTCATCCATGA \\ CAACTTTG,
}

(R) CATtGgGgGtAGgAACACGGAAGGC, 237 bp;

All of the PCR reactions were started with heating $95^{\circ} \mathrm{C}$ for $2 \mathrm{~min}$, followed by the repeated cycle of $95^{\circ} \mathrm{C}$ for $30 \mathrm{sec}, 57-61^{\circ} \mathrm{C}$ for $45 \mathrm{sec}$ and $72^{\circ} \mathrm{C}$ for $1 \mathrm{~min}$, with additional $72^{\circ} \mathrm{C}$ for $10 \mathrm{~min}$. After repeated thermal reactions for 30 cycles, the PCR products were separated by gel electrophoresis with $1 \%$ agarose containing $5 \mu \mathrm{g} / \mathrm{mL}$ of ethidium bromide.

\section{Statistical analysis}

All values were expressed as the means \pm SEM and statistical significance was evaluated by one-way analysis of variance (ANOVA) followed by Scheffe test, StudentNewman-Keuls test or Student's $t$-test (Stat View version 5.0, SAS Institute Inc., USA). Statistical differences were considered with significance at $P<0.05$.

\begin{abstract}
Abbreviations
5-HT: 5-hydroxytriptamine; 5- $\mathrm{HT}_{1 \mathrm{~A}} \mathrm{R}$ : 5-hydroxytriptamine $1 \mathrm{~A}$ receptor; AADC: L-amino acid decarboxylase; DA: Dopamine; DAT: Dopamine transporter; DOPAC: 3,4-dihydroxyphenylacetic acid; ECD: Electrochemical detector; GAPDH: Glyceraldehyde phosphate dehydrogenase; HPLC: High performance liquid chromatography; HVA: Homovanillic acid; L-dopa: L-3,4-dihydroxyphenylalanine; mPFC: Medial prefrontal cortex; MPTP: 1-methyl-4-phenyl-1,2,3,6-tetrahydropyridine; NAR: Noradrenaline receptor; NaSSA: Noradrenergic and specific serotonergic antidepressant; PCR: Polymerase chain reaction; PD: Parkinson's disease; PVDF: Polyvinylidene difluoride; SDS-PAGE: Sodium dodecyl sulfate-polyacrylamide gel electrophoresis; SNc: Substantia nigra pars compacta; SSRI: Serotonin-reuptake inhibitor; TBST: Tris-buffered saline containing 0.1\% Tween 20; TCA: Tricyclic antidepressant; TH: Tyrosine hydroxylase; VMAT2: Vesicular monoamine transporter 2 .
\end{abstract}

\section{Competing interests}

The authors declare that they have no competing interests.

\section{Authors' contributions}

NK and SO equally contributed to this work, performed drug treatment, behavioral testing, HPLC, western blot, statistical analysis, and wrote a part of the manuscript. YY, AT and HY performed a part of behavioral testing and data analysis. MS and TF performed RNA isolation and RT-PCR. JK conceived, designed and supervised all the experiments, and prepared the manuscript. All the authors read and approved the final manuscript.

\section{Acknowledgements}

The authors thank Mr. Gary W. Guzik for English proofreading. This study was supported by an ordinary grant in The University of Tokushima for research and education in each laboratory.

Received: 14 May 2014 Accepted: 19 June 2014

Published: 25 June 2014

\section{References}

1. Samii A, Nutt JG, Ransom B: Parkinson's disease. Lancet 2004, 363:1783-1793.

2. Bernheimer $H$, Birkmayer W, Hornykiewicz O, Jellinger $K$, Seitelberger $F$ : Brain dopamine and the syndromes of Parkinson and Huntington. Clinical, morphological and neurochemical correlations. J Neurol Sci 1973, 20:415-455.

3. Agid Y: Parkinson's disease: pathophysiology. Lancet 1991, 337:1321-1324.

4. Miyasaki JM, Martin W, Suchowersky O, Weiner WJ, Lang AE: Practice parameter: initiation of treatment for Parkinson's disease: an evidence-based review: report of the Quality Standards Subcommittee of the American Academy of Neurology. J Neurol 2002, 58:11-17.

5. Jain L, Benko R, Safranek S: Clinical inquiry. Which drugs work best for early Parkinson's disease? J Fam Pract 2012, 61:106-108.

6. Rascol O, Fabre N: Dyskinesia: L-dopa-induced and tardive dyskinesia. Clin Neuropharmacol 2001, 24:313-323.

7. Mathur BN, Lovinger DM: Serotonergic action on dorsal striatal function. Parkinsonism Relat Disord 2012, 18(Suppl 1):129-131.

8. Cheshire PA, Williams DR: Serotonergic involvement in levodopa-induced dyskinesias in Parkinson's disease. J Clin Neurosci 2012, 19:343-348.

9. Prinssen EP, Colpaert FC, Koek W: 5-HT1A receptor activation and anti-cataleptic effects: high-efficacy agonists maximally inhibit haloperidol-induced catalepsy. Eur J Pharmacol 2002, 453:217-221.

10. Neal-Beliveau BS, Joyce JN, Lucki I: Serotonergic involvement in haloperidol-induced catalepsy. J Pharmacol Exp Ther 2003, 265:207-217.

11. Ohno Y: Therapeutic role of 5-HT1A receptors in the treatment of schizophrenia and Parkinson's disease. CNS Neurosci Ther 2011, 17:58-65.

12. Holm KJ, Markham A: Mirtazapine: a review of its use in major depression. Drugs 1999, 57:607-631.

13. De Boer T: The effects of mirtazapine on central noradrenergic and serotonergic neurotransmission. Int Clin Psychopharmacol 1996, 10(Suppl 4):19-23.

14. De Boer T: The pharmacologic profile of mirtazapine. J Clin Psychiatry 1996, 57(Suppl 4):19-25.

15. Bremner JD: A double-blind comparison of Org 3770, amitriptyline, and placebo in major depression. J Clin Psychiatry 1995, 56:519-525.

16. van Moffaert M, de Wilde J, Vereecken A, Dierick M, Evrard JL, Wilmotte J, Mendlewicz J: Mirtazapine is more effective than trazodone: a double-blind controlled study in hospitalized patients with major depression. Int Clin Psychopharmacol 1995, 10:3-9.

17. Fawcett J, Barkin RL: Review of the results from clinical studies on the efficacy, safety and tolerability of mirtazapine for the treatment of patients with major depression. J Affect Disord 1998, 51:267-285.

18. Amini H, Aghayan S, Jalili SA, Akhondzadeh S, Yahyazadeh O, Pakravan-Nejad $\mathrm{M}$ : Comparison of mirtazapine and fluoxetine in the treatment of major depressive disorder: a double-blind, randomized trial. J Clin Pharm Ther 2005, 30:133-138.

19. Høyberg OJ, Maragakis B, Mullin J, Norum D, Stordall E, Ekdahl P, Ose E, Moksnes KM, Sennef C: A double-blind multicentre comparison of mirtazapine and amitriptyline in elderly depressed patients. Acta Psychiatr Scand 1996, 93:184-190.

20. Nakayama K, Sakurai T, Katsu H: Mirtazapine increases dopamine release in prefrontal cortex by 5-HT1A receptor activation. Brain Res Bull 2004, 63:237-241.

21. Gordon PH, Pullman SL, Louis ED, Frucht SJ, Fahn S: Mirtazapine in Parkinsonian tremor. Parkinsonism Relat Disord 2002, 9:125-126.

22. Fox SH: Non-dopaminergic treatments for motor control in Parkinson's disease. Drugs 2013, 73:1405-1415.

23. Kasahara J, Choudhury ME, Yokoyama H, Kadoguchi N, Nomoto M: Neurotoxin 1-methyl-4-phenyl-1,2,3,6-tetrahydropyridine (MPTP)-induced animal models for Parkinson's disease. In Animal Models for The Study of Human Disease. Edited by Conn PM. London: Academic Press; 2013:633-650 
24. Yokoyama H, Kuroiwa H, Kasahara J, Araki T: Neuropharmacological approach against MPTP (1-methyl-4-phenyl-1,2,3,6-tetrahydropyridine)induced mouse model of Parkinson's disease. Acta Neurobiol Exp 2011, 71:269-280.

25. Yokoyama H, Yano R, Kuroiwa H, Tsukada T, Uchida H, Kato H, Kasahara J, Araki T: Therapeutic effect of a novel anti-parkinsonian agent zonisamide against MPTP (1-methyl-4-phenyl-1,2,3,6-tetrahydropyridine) neurotoxicity in mice. Metab Brain Dis 2010, 25:135-143.

26. Yabe H, Choudhury ME, Kubo M, Nishikawa N, Nagai M, Nomoto M: Zonisamide increases dopamine turnover in the striatum of mice and common marmosets treated with MPTP. J Pharmacol Sci 2009, 110:64-68.

27. Grenhoff J, Svensson TH: Prazosin modulates the firing pattern of dopamine neurons in rat ventral tegmental area. Eur J Pharmacol 1993, 233:79-84.

28. Kapur S, Remington G: Serotonin-dopamine interaction and its relevance to schizophrenia. Am J Psychiatry 1996, 153:466-476.

29. Blier P: Crosstalk between the norepinephrine and serotonin systems and its role in the antidepressant response. J Psychiatry Neurosci 2001, 26(Suppl):3-10.

30. Blandini F, Armentero MT: Animal models of Parkinson's disease. FEBS J 2012, 279:1156-1166.

31. Rose S, Nomoto M, Kelly E, Kilpatrick G, Jenner P, Marsden CD: Increased caudate dopamine turnover may contribute to the recovery of motor function in marmosets treated with the dopaminergic neurotoxin MPTP. Neurosci Lett 1989, 101:305-310.

32. Gainetdinov RR, Caron MG: Monoamine transporters: from genes to behavior. Annu Rev Pharmacol Toxicol 2003, 43:261-284.

33. Leviel V: Dopamine release mediated by the dopamine transporter, facts and consequences. J Neurochem 2011, 118:475-489.

34. Dazzi L, Spiga F, Pira L, Ladu S, Vacca G, Rivano A, Jentsch JD, Biggio G: Inhibition of stress- or anxiogenic-drug-induced increases in dopamine release in the rat prefrontal cortex by long-term treatment with antidepressant drugs. J Neurochem 2001, 76:1212-1220.

35. Anttila SA, Leinonen $\mathrm{EV}$ : A review of the pharmacological and clinical profile of mirtazapine. CNS Drug Rev 2001, 7:249-264.

36. Di Giovanni G, Esposito E, Di Matteo V: Role of serotonin in central dopamine dysfunction. CNS Neurosci Ther 2010, 16:179-194.

37. Sharp T, Boothman L, Raley J, Quérée P: Important messages in the 'post': recent discoveries in 5-HT neurone feedback control. Trends Pharmacol Sci 2007, 28:629-636.

38. Ferguson MC, Nayyar T, Deutch AY, Ansah TA: 5-HT2A receptor antagonists improve motor impairments in the MPTP mouse model of Parkinson's disease. Neuropharmacology 2010, 59:31-36.

39. Mignon L, Wolf WA: Postsynaptic 5-HT1A receptors mediate an increase in locomotor activity in the monoamine-depleted rat. Psychopharmacology 2002, 163:85-94.

40. Ishibashi T, Ohno Y: Antiparkinsonian actions of a selective 5-HT1A agonist, tandospirone, in rats. Biog Amines 2004, 8:329-338.

41. Dupre KB, Eskow KL, Barnum CJ, Bishop C: Striatal 5-HT1A receptor stimulation reduces D1 receptor-induce dyskinesia and improves movement in the hemiparkinsonian rat. Neuropharmacology 2008, 55:1321-1328.

42. Shimizu S, Tatara A, Imaki J, Ohno Y: Role of cortical and striatal 5-HT1A receptors in alleviating antipsychotic-induced extrapyramidal disorders. Prog Neuro-Psychopharmacol Biol Psychiat 2010, 34:877-881.

43. El Mansari M, Guiard BP, Chernoloz O, Ghanbari R, Katz N, Blier P: Relevance of norepinephrine-dopamine interactions in the treatment of major depressive disorder. CNS Neurosci Ther 2010, 16:e1-17.

44. Ogawa N, Asanuma M, Miyazaki I, Diaz-Corrales F, Miyoshi K: L-DOPA treatment from the viewpoint of neuroprotection: Possible mechanism of specific and progressive dopaminergic neuronal death in Parkinson's disease. J Neurol 2005, 252(Suppl 4):iv23-iv31.

45. Ahlskog JE, Munenter MD: Frequency of levodoparelated dyskinesias and motor fluctuations as estimated from the cumulative literature. Mov Disord 2001, 16:448-458.

46. Inden M, Abe M, Minamino H, Takata K, Yoshimoto K, Tooyama I, Kitamura $Y$ : Effect of selective serotonin reuptake inhibitors via 5 -HT1A receptors on L-DOPA-induced rotational behavior in a hemiparkinsonian rat model. J Pharmacol Sci 2012, 119:10-19.

47. Johnston TH, Fox SH, Piggott MJ, Savola JM, Brotchie JM: The a2 adrenergic antagonist fipamezole improves quality of levodopa action in Parkinsonian primates. Mov Disord 2012, 25:2084-2093.
48. Costa FH, Rosso AL, Maultasch H, Nicaretta DH, Vincent MB: Depression in Parkinson's disease: diagnosis and treatment. Arq Neuropsiquiatr 2012, 70:617-620

49. Perez-Lloret S, Rascol O: Parkinson disease: Serotonin reuptake inhibitors for depression in PD. Nat Rev Neurol 2012, 8:365-366.

50. Goodnick PJ, Hernandez M: Treatment of depression in comorbid medical illness. Expert Opin Pharmacother 2000, 1:1367-1384.

51. Kadoguchi N, Umeda M, Kato H, Araki T: Proteasome Inhibitor Does Not Enhance MPTP Neurotoxicity in Mice. Cell Mol Neurobiol 2008, 28:971-979.

52. Allbutt HN, Henderson JM: Use of the narrow beam test in the rat, 6-hydroxydopamine model of Parkinson's disease. J Neurosci Methods 2007, 159:195-202.

53. Araki T, Mikami T, Tanji H, Matsubara M, Imai Y, Mizugaki M, Itoyama Y: Biochemical and immunohistological changes in the brain of 1-methyl4-phenyl-1,2,3,6-tetrahydropyridine (MPTP)-treated mouse. Eur J Pharm Sci 2001, 12:231-238.

54. Kurosaki R, Muramatsu Y, Kato H, Araki T: Biochemical, behavioral and immunohistochemical alterations in MPTP-treated mouse model of Parkinson's disease. Pharmacol Biochem Behav 2004, 78:143-153.

55. Takagi S, Hayakawa N, Kimoto H, Kato H, Araki T: Damage of oligodendrocytes in the striatum after MPTP neurotoxicity in mice. J Neural Transm 2007, 114:1553-1557.

doi:10.1186/1471-2202-15-79

Cite this article as: Kadoguchi et al:: Mirtazapine has a therapeutic potency in 1-methyl-4-phenyl-1,2,3,6-tetrahydropyridine (MPTP)induced mice model of Parkinson's disease. BMC Neuroscience 2014 15:79.

\section{Submit your next manuscript to BioMed Central and take full advantage of:}

- Convenient online submission

- Thorough peer review

- No space constraints or color figure charges

- Immediate publication on acceptance

- Inclusion in PubMed, CAS, Scopus and Google Scholar

- Research which is freely available for redistribution 